Volume 3, Issue 9, September-2016, pp. 492-499 ISSN (0): 2349-7084

International Journal of Computer Engineering In Research Trends

IJCERT

Available online at: www.ijcert.org

\title{
Optimization of Resistance Spot Welding of 304 Steel Using GRA
}

\author{
M.R. Rawal*, R.R. Kolhapure, S.S. Sutar, V.D. Shinde \\ *Corresponding Author: manjunathrrawal61@gmail.com \\ Department of Mechanical Engineering, DKTE Society's Textile and Engineering Institute, \\ Ichalkaranji, -416115(India)
}

\begin{abstract}
Resistance spot welding (RSW) quality is mainly depends upon the parameters and their levels selected, like welding current, electrode force and welding time etc. So selection of optimal parameter levels plays an important role. Therefore, optimization of weld tensile strength and nugget diameter is selected for study. In this paper, use of Taguchi with Grey relational analysis (GRA) method to determine significant process parameters and their levels for optimal tensile shear strength (T-S) and nugget diameter (N-D) is reported. Taguchi based L27 (33) orthogonal array is selected for experimentation. Experiments are carried out on Stainless Steel 304. The level of importance of the welding parameters on the tensile shear strength and nugget diameter is determined by using analysis of variance (ANOVA) using Minitab 16 software. To improve the spot weld quality (i.e. T-S and N-D) multi objective process parameter optimization is performed using grey relational analysis.
\end{abstract}

Index Terms-Resistance Spot Welding (RSW), Tensile shear strength, Nugget diameter, Taguchi Method, Grey Relational Analysis

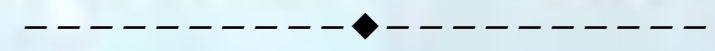

\section{INTRODUCTION}

$\mathrm{R}$

esistance spot welding process, in which coalescence of metal is produced at the faying surfaces by the heat generated at the joint by the contact resistance to the flow of electric current. The materials to be joined are brought together under pressure by a pair of electrodes. A high electric current passes through the workpiece between the electrodes. Due to contact resistance and joule heating, a molten weld nugget is formed in the work pieces. The amount of heat produced is a function of current, time and resistance between the workpieces. It is desirable to have the maximum temperature at the interface of the parts to be joined. Therefore, the resistance of the workpieces and the contact resistance between theelectrodes and work should be kept as low as possible with respect to the resistance between the faying surfaces [1]. The principle of working is as shown in Fig.1.

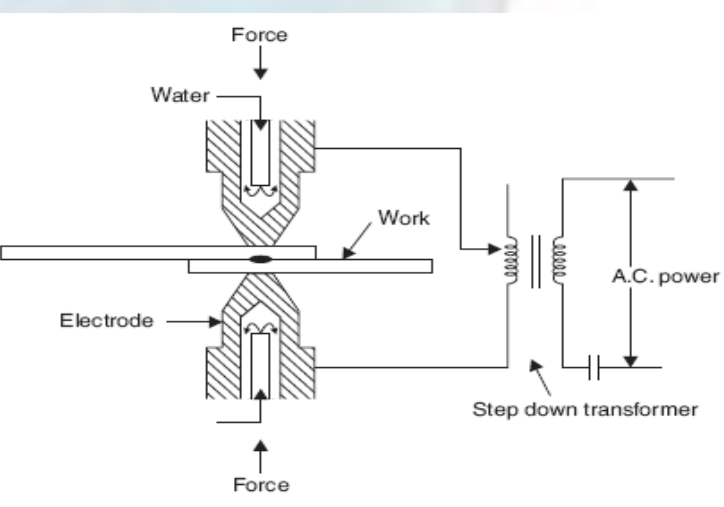

Fig. 1: Working Principle of Resistance Spot Welding

As the name implies, it uses the resistance of the materials to the flow of current that causes localized heating between the parts to be joined. Excessive heat in the electrodes reduces the electrode cap life and deteriorates the weld quality. Hence, the electrodes are cooled via water circulation through channels opened inside them [1]. The temperature and resistance obtained during resistance spot welding operation is as shown in Fig.2. Where R1, R2, R3 
M.R. Rawal et.al ," Optimization of Resistance Spot Welding of 304 Steel Using GRA", International Journal of Computer Engineering In Research Trends, Volume 3, Issue 9, September-2016, pp. 492-499

are the resistances at the Electrode tip and plate surface, Resistance of joining plates, Resistance at the interface of two plates respectively.

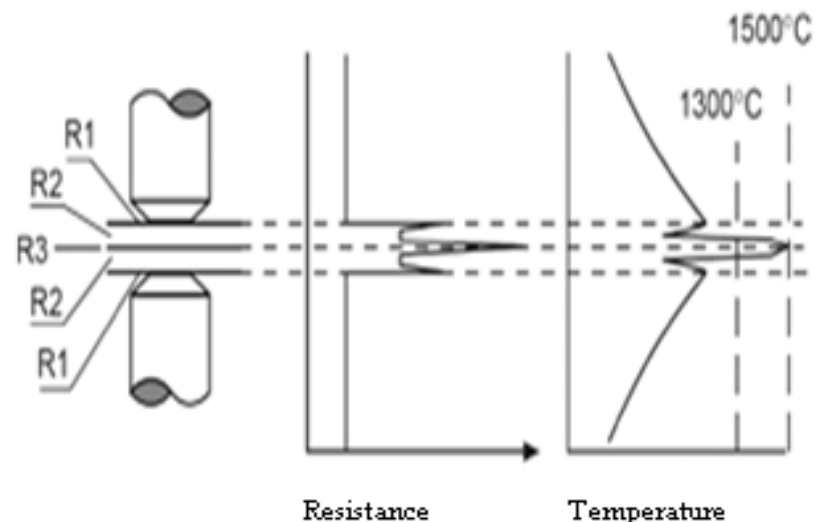

Fig. 2: Resistance and Temperature Distribution Curve

Resistance spot-welding is widely used as an efficient joining technology for assembling sheet metal components in the automotive industry. One priority of these industries is the production of high-quality spot welds to ensure the stability and safety of their products. One way to produce high-quality spot weld joints is to monitor the welding parameters such as voltage, welding current, electrode pressure, time, surface condition, etc. [2].

To predict the welding parameters accurately without consuming time, materials and labor efforts, there are various methods of obtaining the desired output variables through model development. Using appropriate statistical technique such as Taguchi Method (TM) and ANOVA, the number of unnecessary experiments can be reduced and the statistical significance of parameters can be safely identified.

There are many parameters which control the quality of resistance spot welding; Effect of these parameters is easily understood by cause and effect diagram as shown in Fig.3

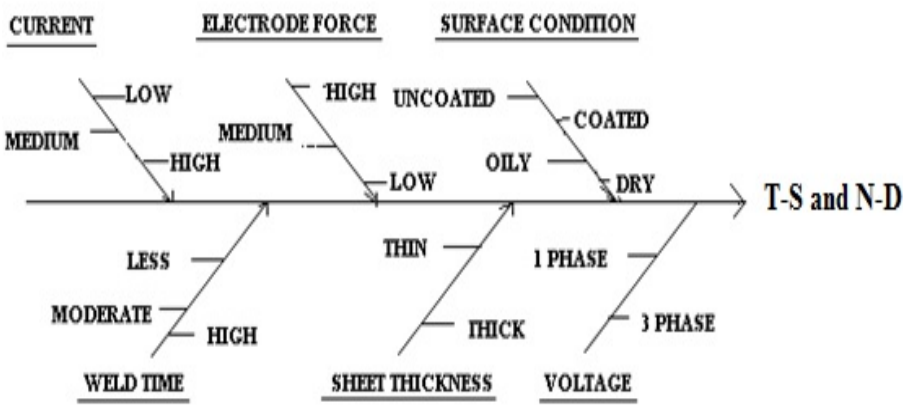

Fig.3: Cause and Effect Diagram for RSW

\subsection{HEAT GENERATION IN RSW}

There are three main parameters which affects the amount of heat generated in RSW namely, Welding current, contact resistance and weld time. In order to produce good quality weld the above parameters must be controlled properly. The amount of heat generated in this process is governed by the Eq.1.

$$
Q=I^{2} R T
$$

Where, $Q=$ Heat generated $(\mathrm{J}), \mathrm{I}=$ Current $(\mathrm{A})$

$\mathrm{R}=$ Resistance of the work piece $(\Omega)$

$\mathrm{T}=$ Time of current flow (Sec or Cycle).

\section{EXPERIMENTAL WORK}

The specimens were cut from a sheet metal and cut parallel to the rolling action of the sheets. The dimensions are $100 \mathrm{~mm}$ length (L) and $30 \mathrm{~mm}$ width $(\mathrm{W})$, the overlap being equal to the width of the specimen. This overlap was chosen as per American Welding Society (AWS) recommendation as shown in Fig.4 [2]. The material used in the present work is Stainless Steel (304 grade) sheet of $1 \mathrm{~mm}$ thickness.

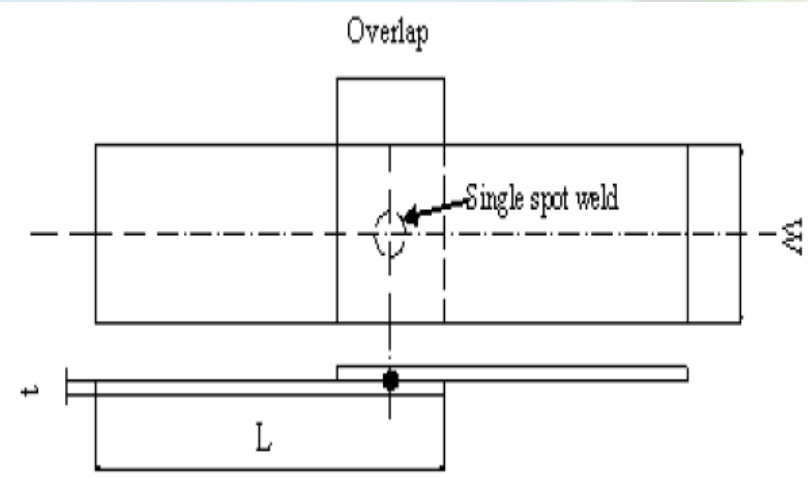

Fig.4: Specimen as per AWS

\subsection{Chemical Composition}

The chemical composition for each element of the above material is listed in Table 1.

Table 1: Chemical composition of Stainless Steel

\begin{tabular}{|c|c|c|c|c|c|c|c|c|c|}
\hline $\begin{array}{l}\text { Con- } \\
\text { tent }\end{array}$ & C & $\mathrm{Si}$ & $\mathrm{Mn}$ & $\mathrm{P}$ & $S$ & $\mathrm{Cr}$ & Mo & $\mathrm{Ni}$ & $\mathrm{Fe}$ \\
\hline $\begin{array}{c}\text { Value } \\
(\%)\end{array}$ & 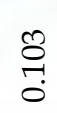 & 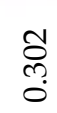 & $\stackrel{\text { }}{\curvearrowright}$ & 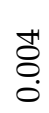 & $\begin{array}{l}\text { o } \\
8 \\
8 \\
0\end{array}$ & $\begin{array}{l}\stackrel{2}{\circ} \\
\stackrel{0}{9}\end{array}$ & $\begin{array}{l}\hat{\vartheta} \\
0 \\
0\end{array}$ & $\begin{array}{l}\infty \\
\infty \\
\infty\end{array}$ & $\stackrel{m}{R}$ \\
\hline
\end{tabular}

\subsection{Selection of Orthogonal Array (OA)}

Experiments were designed using Taguchi method which uses an orthogonal array (OA) to study limited number of experiments. In the present research three process parameters (factor) were chosen, all of them were set at three different levels shown in Table 2. 
M.R. Rawal et.al ," Optimization of Resistance Spot Welding of 304 Steel Using GRA", International Journal of Computer Engineering In Research Trends, Volume 3, Issue 9, September-2016, pp. 492-499

Table 2: Process Parameters and Levels

\begin{tabular}{|c|c|c|c|c|c|}
\hline $\begin{array}{c}\text { Sr. } \\
\text { No }\end{array}$ & $\begin{array}{c}\text { Process Pa- } \\
\text { rameters }\end{array}$ & Parameter & $\begin{array}{c}\text { Level } \\
1\end{array}$ & $\begin{array}{c}\text { Level } \\
2\end{array}$ & $\begin{array}{c}\text { Level } \\
3\end{array}$ \\
\hline 1 & $\begin{array}{c}\text { Welding Cur- } \\
\text { rent (KA) }\end{array}$ & A & 4.8 & 5.9 & 7 \\
\hline 2 & $\begin{array}{c}\text { Electrode } \\
\text { Force (KN) }\end{array}$ & B & 0.490 & 0.539 & 0.588 \\
\hline 3 & $\begin{array}{c}\text { Welding } \\
\text { Time (cycle) }\end{array}$ & C & 45 & 50 & 55 \\
\hline
\end{tabular}

The selection of a particular OA is based on the number of levels of various factors. Here for experimentation L27 taguchi orthogonal array is selected for three process parameters and three levels of each. The photograph of spot welded specimen according to L27 Array is shown in Fig.5. Each experiment is carried out for three times to find effect of process parameters at different levels on performance characteristics.

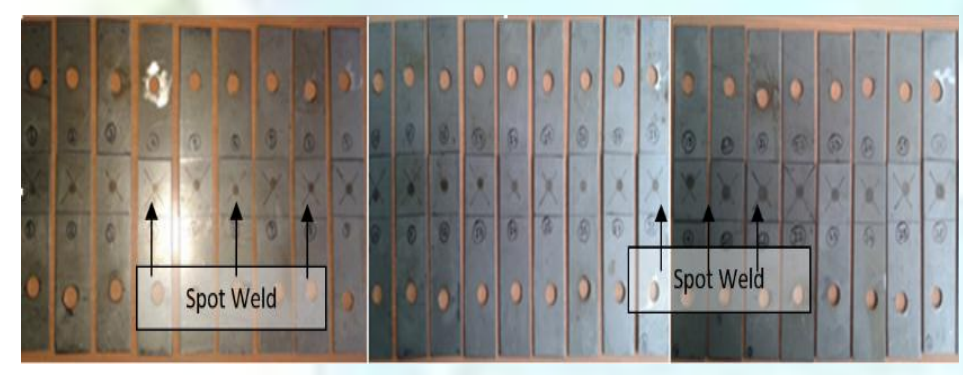

Fig. 5: Photograph of Spot Welded Specimens

The tensile shear strength and nugget diameter tests are carried out on UTM and Dynascan optical profile meter as shown in Fig.6. Tensile strength and Nugget Diameter values for each run are noted in Table 3. These values are average of three experiments carried out at each parameter setting during experimentations.
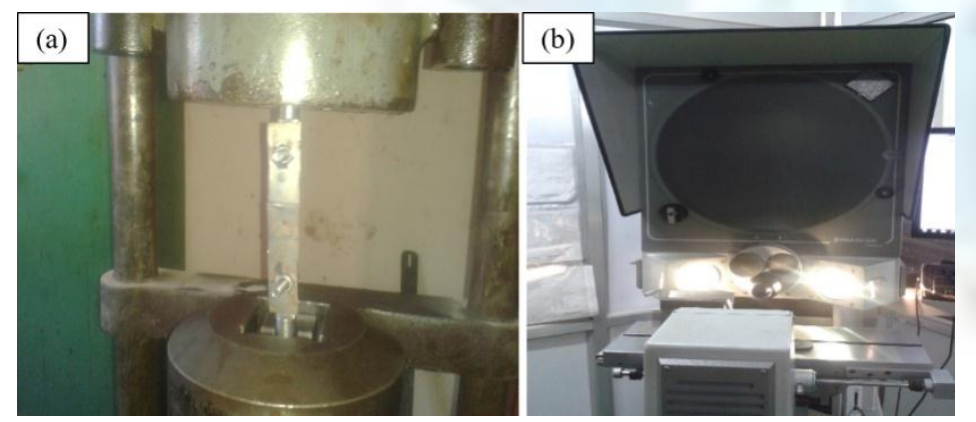

Fig. 6: Photograph of (a) Tensile Shear Test

(b) Nugget diameter measurement

\subsection{ANALYSIS OF S/N RATIOS:}

Taguchi recommends analyzing data using the
$\mathrm{S} / \mathrm{N}$ ratio that will offer two advantages; it provides guidance for selection of optimum level based on least variation around on the average value, which closest to target and also it offers objective comparison of two sets of experimental data with respect to deviation of the average from the target. The experimental results are analyzed to investigate the main effects.

Table 3: Orthogonal array with response variable data and $\mathrm{S} / \mathrm{N}$ ratios

\begin{tabular}{|c|c|c|c|c|c|c|c|}
\hline \multirow{2}{*}{$\begin{array}{l}\text { Sr. } \\
\text { No }\end{array}$} & A & B & C & \multirow{2}{*}{$\begin{array}{c}\text { T-S } \\
(\mathrm{kN})\end{array}$} & $\begin{array}{c}\text { N-D } \\
(\mathrm{mm})\end{array}$ & \multicolumn{2}{|c|}{ S/N Ratio } \\
\cline { 7 - 9 } & & & & & T-S & N-D \\
\hline 1 & 4.8 & 0.490 & 45 & 3.860 & 3.140 & 11.732 & 9.939 \\
\hline 2 & 4.8 & 0.490 & 50 & 3.602 & 3.527 & 11.131 & 10.948 \\
\hline 3 & 4.8 & 0.490 & 55 & 3.840 & 4.820 & 11.687 & 13.661 \\
\hline 4 & 4.8 & 0.539 & 45 & 3.654 & 3.527 & 11.255 & 10.948 \\
\hline 5 & 4.8 & 0.539 & 50 & 3.658 & 3.711 & 11.265 & 11.390 \\
\hline 6 & 4.8 & 0.539 & 55 & 3.974 & 3.909 & 11.985 & 11.841 \\
\hline 7 & 4.8 & 0.588 & 45 & 3.826 & 3.909 & 11.655 & 11.841 \\
\hline 8 & 4.8 & 0.588 & 50 & 3.836 & 4.098 & 11.678 & 12.251 \\
\hline 9 & 4.8 & 0.588 & 55 & 4.021 & 3.990 & 12.087 & 12.019 \\
\hline 10 & 5.9 & 0.490 & 45 & 5.333 & 4.556 & 14.539 & 13.172 \\
\hline 11 & 5.9 & 0.490 & 50 & 4.993 & 4.583 & 13.967 & 13.223 \\
\hline 12 & 5.9 & 0.490 & 55 & 4.941 & 4.860 & 13.876 & 13.733 \\
\hline 13 & 5.9 & 0.539 & 45 & 4.653 & 4.664 & 13.355 & 13.375 \\
\hline 14 & 5.9 & 0.539 & 50 & 5.136 & 4.855 & 14.213 & 13.724 \\
\hline 15 & 5.9 & 0.539 & 55 & 5.277 & 4.860 & 14.448 & 13.733 \\
\hline 16 & 5.9 & 0.588 & 45 & 5.035 & 4.610 & 14.040 & 13.274 \\
\hline 17 & 5.9 & 0.588 & 50 & 5.136 & 4.725 & 14.213 & 13.488 \\
\hline 18 & 5.9 & 0.588 & 55 & 5.308 & 5.012 & 14.499 & 14.000 \\
\hline 19 & 7.0 & 0.490 & 45 & 5.680 & 4.700 & 15.087 & 13.442 \\
\hline 20 & 7.0 & 0.490 & 50 & 5.780 & 4.846 & 15.239 & 13.708 \\
\hline 21 & 7.0 & 0.490 & 55 & 5.737 & 5.300 & 15.174 & 14.486 \\
\hline 22 & 7.0 & 0.539 & 45 & 5.631 & 5.388 & 15.012 & 14.629 \\
\hline 23 & 7.0 & 0.539 & 50 & 5.649 & 5.100 & 15.039 & 14.151 \\
\hline 24 & 7.0 & 0.539 & 55 & 6.680 & 5.468 & 16.496 & 14.757 \\
\hline 25 & 7.0 & 0.588 & 45 & 5.590 & 5.312 & 14.948 & 14.505 \\
\hline 26 & 7.0 & 0.588 & 50 & 6.046 & 6.231 & 15.629 & 15.891 \\
\hline 27 & 7.0 & 0.588 & 55 & 6.194 & 5.806 & 15.839 & 15.278 \\
\hline & & & & & & & \\
\hline
\end{tabular}

According to quality engineering the characteristics are classified as Higher the better $(\mathrm{HB})$ and lower the better (LB). HB includes T-S strength and Nugget diameter which desires higher values. Similarly LB includes Heat Affected Zone (HAZ) for which lower value is preferred [3]. Results of S/N ratios are represented in Table 3 by using Eq.2.

Higher the better:

$$
\eta=-10 \log \frac{1}{N} \sum_{i=1}^{n} \frac{1}{Y^{2}}
$$


M.R. Rawal et.al ," Optimization of Resistance Spot Welding of 304 Steel Using GRA", International Journal of Computer Engineering In Research Trends, Volume 3, Issue 9, September-2016, pp. 492-499

Lower the better:

$$
\eta=-10 \log \frac{1}{N} \sum_{i=1}^{n} Y^{2}
$$

Where, $\mathrm{N}=$ No. of experiments

$\mathrm{Y}=$ Response variable

\subsection{ANALYSIS OF VARIANCE (ANOVA):}

ANOVA is carried out for finding most significant process parameters which will affect output quality characteristics. S/N values of response variables are used for obtaining ANOVA by using Minitab 16 software. Results are shown in Table $4 \& 5$ for T-S and N-D for higher the better characteristic. According to this analysis, the most significant parameter with respect to T-S and N-D is welding current. Whereas welding time and electrode force is least significant. Percent contribution indicates the relative power of a factor to reduce variation. For a factor with a high percent contribution, a small variation will have a great influence on the performance [3],[4].

Table 4: ANOVA for Tensile -Shear Strength

\begin{tabular}{|c|c|c|c|c|c|c|}
\hline Source & DOF & Seq SS & $\begin{array}{c}\text { Adj } \\
\text { MS }\end{array}$ & F & P & $\%$ C \\
\hline A (kA) & 2 & 66.574 & 33.287 & 261.34 & 0.000 & 94.21 \\
\hline B (kN) & 2 & 0.2727 & 0.1364 & 1.07 & 0.362 & 0.39 \\
\hline $\begin{array}{c}\text { C } \\
\text { (cycle) }\end{array}$ & 2 & 1.2711 & 0.6355 & 4.99 & 0.017 & 1.80 \\
\hline Error & 20 & 2.5474 & 0.1274 & - & - & 3.60 \\
\hline Total & 26 & 70.6652 & - & - & - & 100 \\
\hline
\end{tabular}

Table 5: ANOVA for Nugget Diameter

\begin{tabular}{|c|c|c|c|c|c|c|}
\hline Source & DOF & Seq SS & Adj MS & F & P & $\%$ C \\
\hline A (kA) & 2 & 38.689 & 19.3444 & 51.01 & 0.000 & 73.81 \\
\hline B (kN) & 2 & 2.220 & 1.1098 & 2.93 & 0.077 & 4.23 \\
\hline $\begin{array}{c}\text { C } \\
\text { (cycle) }\end{array}$ & 2 & 3.925 & 1.9627 & 5.18 & 0.015 & 7.49 \\
\hline Error & 20 & 7.585 & 0.3792 & - & - & 14.47 \\
\hline Total & 26 & 52.418 & - & - & - & 100 \\
\hline
\end{tabular}

Fig. 7 (a) \& (b) shows main effect plot for N-D and T-S. Here larger signal to noise ratio is considered as better one, hence values of plot at top positions indicate better results.
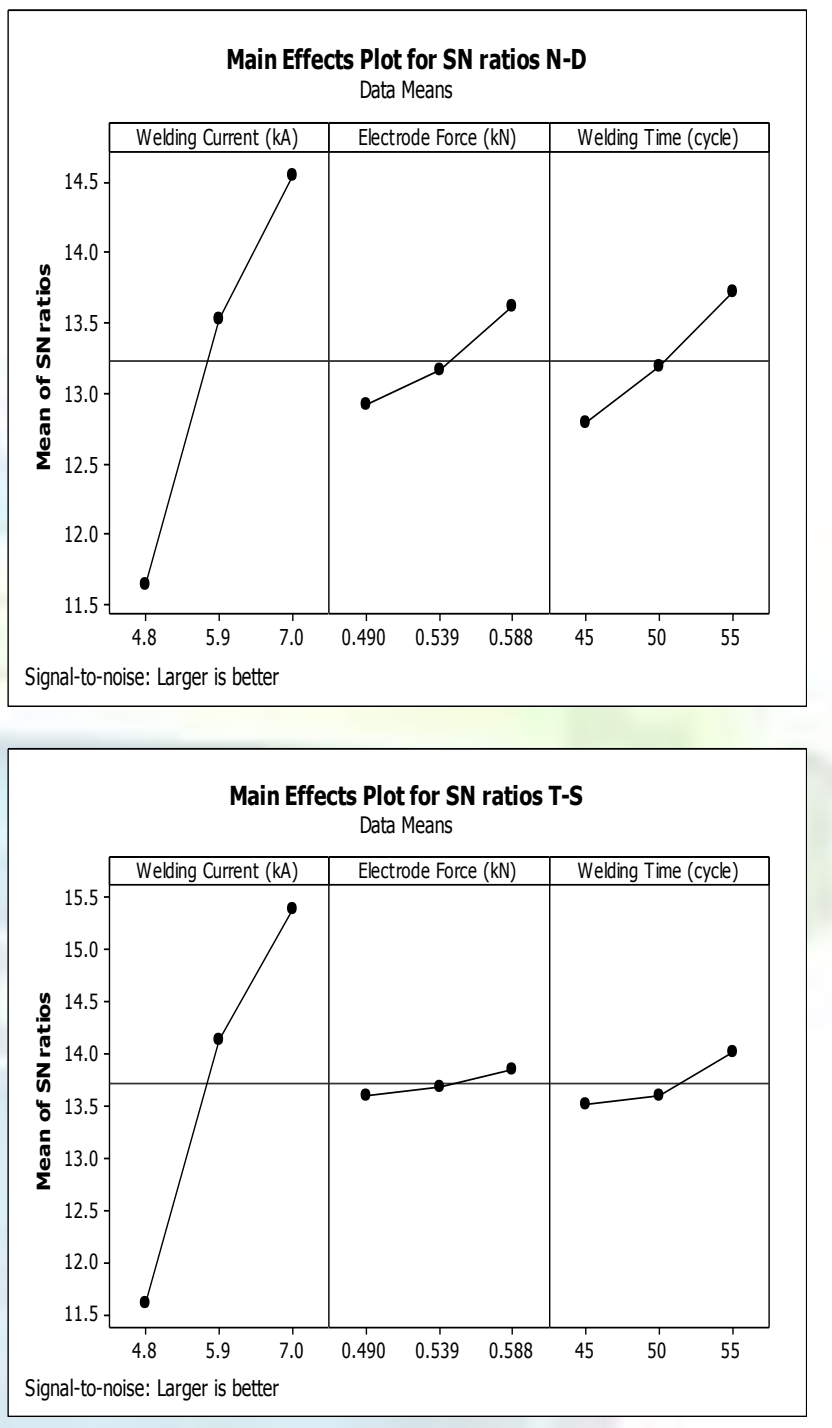

Fig. 7: Main Effects Plot of S/N Ratios for: (a) N-D Strength (b) T-S respectively

\section{GREY RELATIONAL ANALYSIS (GRA)}

Taguchi can optimize single response only and unable to use, if the number of responses are more than one [5]. So, Grey Relational Analysis (GRA) method is used for multi response optimization. The multi response optimization converts multiple objectives into single objective [6].Hence grey relational analysis with Taguchi approach has been used to solve multi response optimization.

The optimization of multiple performance characteristics using GRA includes the following steps.

\section{Normalization of $\mathrm{S} / \mathrm{N}$ ratio}

In GRA, normalization of $\mathrm{S} / \mathrm{N}$ ratio is carried out for normalizing the raw data for analysis. A normalization of the $\mathrm{S} / \mathrm{N}$ ratio in the range between zero and one is also 
M.R. Rawal et.al ," Optimization of Resistance Spot Welding of 304 Steel Using GRA", International Journal of Computer Engineering In Research Trends, Volume 3, Issue 9, September-2016, pp. 492-499

called as the grey relational generation [7-8]. Normalization of data for larger-the-better, smaller-the-better and nominal-the-better characteristics are carried out for converting it into identical levels.

If smaller-the-better characteristic used in the original sequence, then it should be normalized as given by Eq.4.

$$
x_{i}^{*}(k)=\frac{\max x_{i}^{0}(k)-x_{i}^{0}(k)}{\max x_{i}^{0}(k)-\min x_{i}^{0}(k)}(4)
$$

If larger-the-better characteristic used in the original sequence, then it should be normalized as given by Eq. 5

$\mathrm{x}_{\mathrm{i}}^{*}(\mathrm{k})=\frac{\mathrm{x}_{\mathrm{i}}^{0}(\mathrm{k})-\min \mathrm{x}_{\mathrm{i}}^{0}(\mathrm{k})}{\max _{\mathrm{i}}^{0}(\mathrm{k})-\min \mathrm{x}_{\mathrm{i}}^{0}(\mathrm{k})}$

In this study both response variables are considered for larger-the-better characteristics. Therefore normalization is done by using Eq.5 and values are shown in Table 9.

For Experiment No.1, Tensile strength:

Nugget diameter:

$$
x_{i}^{*}(k)=\frac{(11.732)-(11.13)}{(16.496)-(11.13)}=0.112
$$

$$
x_{i}^{*}(k)=\frac{(9.94)-(9.94)}{(15.89)-(9.40)}=0.000
$$

All the sequences after normalization are denoted as $x 0^{*}(\mathrm{k})$ and $\mathrm{xi}^{*}(\mathrm{k})$ for reference sequence and comparability sequence, respectively. The larger value of normalized results indicates the better performance characteristic and the best-normalized results will be equal to one.

\section{Deviation sequences}

The deviation sequence which is represented by $\Delta_{o i}(k)$, is the absolute difference between the reference sequence $x_{i}^{0}(k)$ and the comparability sequence $x_{i}^{*}(k)$ after normalization. It is determined by using Eq.6

$$
\Delta_{o i} k=\left|x_{0}^{*}(k)-x_{i}^{*}(k)\right|
$$

For Experiment no.1, Tensile strength

Nugget diameter

$$
\Delta_{o i}(1)=|1.000-0.112|=0.888
$$

$$
\Delta_{o i}(1)=|1.000-0.000|=1.000
$$

\section{Grey Relational Coefficient (GRC)}

GRC for all the sequences gives the relationship between the ideal (best) and actual normalized $\mathrm{S} / \mathrm{N}$ ratio. If the two sequences agree at all points, then GRC will be taken as 1. The GRC can be expressed by Eq.7 [9].

$$
\gamma\left(x_{0}(k), x_{i}(k)\right)=\frac{\Delta_{\min }+\zeta . \Delta_{\max }}{\Delta_{0 i}(k)+\zeta . \Delta_{\max }}
$$

Where,

$\Delta_{\min }=\min \cdot \min \Delta_{0, i}(k)$

$\Delta_{\max }=\max \cdot \max \Delta_{0, i}(k)$

$\Delta_{0 i}(k)$ Is the deviation sequence and

$\zeta=$ distinguishing coefficient, $\zeta \in(0,1)$. And for current research work, $\zeta$ is set as 0.5 .

The Grey relational coefficient $\gamma\left(x_{0}^{*}(1) \cdot x_{0}^{1}(1)\right)$ is calculated by using Eq.7 and subsequent values for all experiments are displayed in Table 9.

For Experiment No.1, Tensile strength:

$$
\gamma\left(x_{0}^{*}(1) \cdot x_{0}^{1}(1)\right)=\frac{0.0000+0.5 \times 1.0000}{0.888+0.5 \times 1.0000}=0.360
$$

Nugget diameter:

$$
\gamma\left(x_{0}^{*}(2) \cdot x_{0}^{1}(2)\right)=\frac{0.0000+0.5 \times 1.0000}{1.000+0.5 \times 1.0000}=0.333
$$

\section{Grey Relational Grade (GRG)}

The overall evaluation of the multiple performance characteristics is based on the GRG. The grey relational grade is an average sum of the GRC, and is calculated using Eq.8 [7-8].

$$
\gamma\left(x_{0}, x_{i}\right)=\frac{1}{m} \sum_{i=1}^{m} \gamma\left(x_{0}(k), x_{i}(k)\right)
$$

Where,

$\gamma\left(x_{0}, x_{i}\right)$ is the Grey relational grade for the $j_{t h}$ experiment and $\mathrm{m}$ is the number of performance characteristics.

Grey relational grade (GRG) for experiment no 1 is calculated as,

$$
\gamma\left(x_{0}, x_{i}\right)=\frac{0.360+0.333}{2}=0.347
$$

The order of experiments according to the magnitude of GRG is depicted in Table 9.

\section{Prediction of GRG under optimum parameters}

After evaluating the optimal parameter settings, the next step is to predict and verify the improvement of quality characteristics using the optimal parametric combination. The optimal Grey relational grade nopt is predicted as follows [10-12].

$$
\eta_{\text {opt }}=\overline{\mathrm{T}}+\left(\overline{\mathrm{A}}_{(1 / 2 / 3)}-\overline{\mathrm{T}}\right)+\left(\overline{\mathrm{B}}_{(1 / 2 / 3)}-\overline{\mathrm{T}}\right)+\left(\overline{\mathrm{C}}_{(1 / 2 / 3)}-\overline{\mathrm{T}}\right)
$$

Where,

$\overline{\mathrm{T}}=$ overall mean of the response

$\overline{\mathrm{A}}_{(1 / 2 / 3)}, \overline{\mathrm{B}}_{(1 / 2 / 3),} \overline{\mathrm{C}}_{(1 / 2 / 3)}=$ Higher values of average response at the first or second or third levels of parameters $\mathrm{A}, \mathrm{B}$ and $\mathrm{C}$ respectively.

$\eta_{\text {opt }}=0.451+(0.715-0.451)+(0.580-0.451)+(0.592$ 
M.R. Rawal et.al ," Optimization of Resistance Spot Welding of 304 Steel Using GRA", International Journal of Computer Engineering In Research Trends, Volume 3, Issue 9, September-2016, pp. 492-499

$=0.98$

The results of confirmation experiment obtained by grey relation analysis are as shown in Table 6.

Table 6: Result of Confirmation Experiment

\begin{tabular}{|c|c|c|c|}
\hline \multirow{3}{*}{ Parameters } & \multirow{2}{*}{$\begin{array}{l}\text { Initial } \\
\text { Parameter } \\
\text { Setting }\end{array}$} & \multicolumn{2}{|c|}{ Optimum Parameter level } \\
\hline & & Prediction & Experiment \\
\hline & A3B3C2 & A3B3C3 & A3B3C3 \\
\hline $\mathrm{A}(\mathrm{kA})$ & 7 & & 7 \\
\hline $\mathrm{B}(\mathrm{kN})$ & 0.588 & & 0.588 \\
\hline C (cycle) & 50 & & 55 \\
\hline T-S (kN) & 6.046 & & 6.531 \\
\hline N-D (mm) & 6.231 & & 6.457 \\
\hline GRG & 0.878 & 0.98 & 0.978 \\
\hline
\end{tabular}

Response Table for Means of GRG is as shown in Table 7, indicates the rank of the process parameters. Here, current is Rank 1 is most influencing parameter, rank 2 is Weld time and rank 3 is electrode force.

Table 7: Response Table for Means of GRG

\begin{tabular}{|c|c|c|c|}
\hline Level & $\begin{array}{c}\text { Welding Cur- } \\
\text { rent }(\mathrm{kA})\end{array}$ & $\begin{array}{c}\text { Electrode } \\
\text { Force }(\mathrm{kN})\end{array}$ & $\begin{array}{c}\text { Weld Time } \\
\text { (cycle) }\end{array}$ \\
\hline 1 & 0.388 & 0.521 & 0.512 \\
\hline 2 & 0.546 & 0.548 & 0.545 \\
\hline 3 & 0.715 & 0.580 & 0.592 \\
\hline Min & 0.388 & 0.521 & 0.512 \\
\hline Max & 0.715 & 0.580 & 0.592 \\
\hline Delta & 0.327 & 0.059 & 0.081 \\
\hline Rank & 1 & 3 & 2 \\
\hline
\end{tabular}

\section{4 .ANOVA fOR GREY RELATIONAL GRADE}

The results of GRG are considered as single response variable for obtaining most significant process parameter for multi response variables i.e. T-S and N-D. The Table 8 shows result of ANOVA obtained from GRG. The F-ratio value indicates the significance of process parameters. Larger the value of F-ratio represent most significance process parameter [11-12]. Here, Welding current is most significant process parameter followed by weld time and electrode force.

Table 8: ANOVA for GRG

\begin{tabular}{|c|c|c|c|c|c|c|}
\hline Source & DOF & Seq SS & Adj MS & F & P & \% C \\
\hline A & 2 & 125.42 & 62.713 & 131.9 & 0.000 & 86.77 \\
\hline B & 2 & 2.834 & 1.416 & 2.98 & 0.074 & 1.97 \\
\hline C & 2 & 6.771 & 3.3854 & 7.12 & 0.005 & 4.68 \\
\hline Error & 20 & 9.508 & 0.4754 & - & - & 6.58 \\
\hline Total & 28 & 144.53 & - & - & - & 100 \\
\hline
\end{tabular}
in Fig. 8. Here, these values of parameters give best results of response variables. While the lower most values in the plot indicate the values of parameters for worst case results.

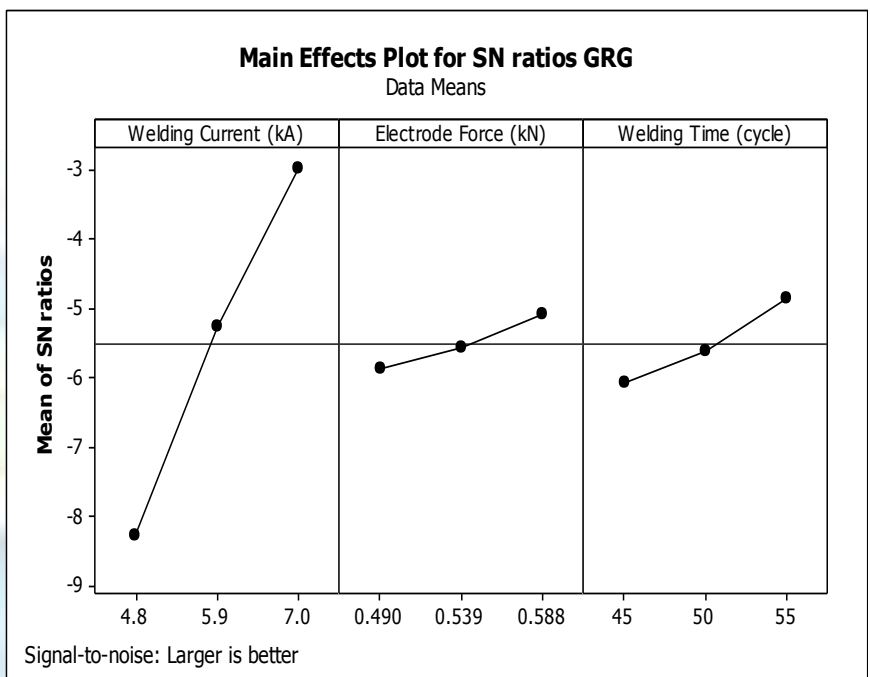

Fig. 8: Main Effects of S/N Ratios for GRG

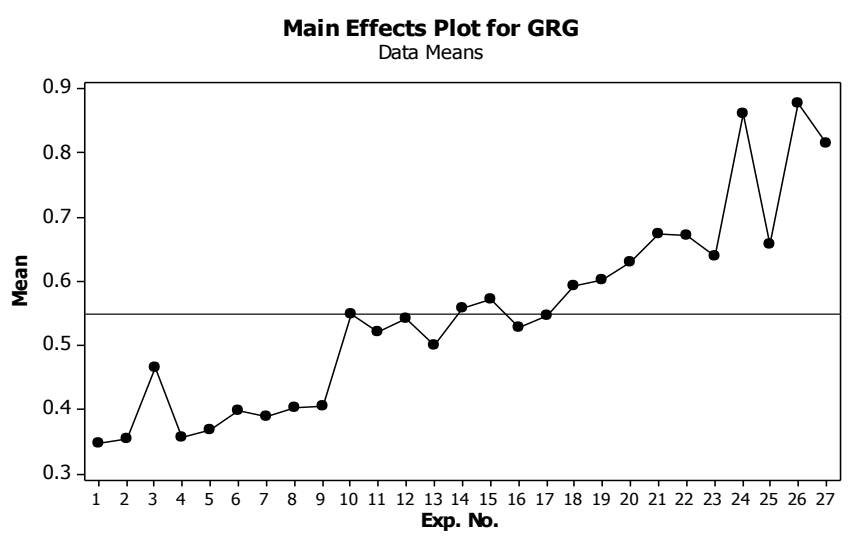

Fig. 9: Main Effects for GRG 
M.R. Rawal et.al ," Optimization of Resistance Spot Welding of 304 Steel Using GRA", International Journal of Computer Engineering In Research Trends, Volume 3, Issue 9, September-2016, pp. 492-499

Table 9: Grey Relational Analysis (GRA)

\begin{tabular}{|c|c|c|c|c|c|c|c|c|c|c|c|c|c|}
\hline \multirow{2}{*}{$\begin{array}{c}\mathrm{Sr} \\
\mathrm{N} \\
\mathrm{O}\end{array}$} & \multirow{2}{*}{ A } & \multirow{2}{*}{ B } & \multirow{2}{*}{$\mathrm{C}$} & \multicolumn{2}{|c|}{ S/N Ratio } & \multicolumn{2}{|c|}{ Normalization } & \multicolumn{2}{|c|}{$\begin{array}{l}\text { Deviation Se- } \\
\text { quence }\end{array}$} & \multicolumn{2}{|c|}{$\begin{array}{c}\text { Grey Relation } \\
\text { Coefficient }\end{array}$} & \multirow{2}{*}{ GRG } & \multirow{2}{*}{ 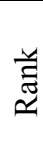 } \\
\hline & & & & (T-S) & $(\mathrm{N}-\mathrm{D})$ & T-S & $\mathrm{N}-\mathrm{D}$ & $\mathrm{T}-\mathrm{S}$ & N-D & $\mathrm{T}-\mathrm{S}$ & $\mathrm{N}-\mathrm{D}$ & & \\
\hline 1 & 4.8 & 0.490 & 45 & 11.732 & 9.939 & 0.112 & 0.000 & 0.888 & 1.000 & 0.360 & 0.333 & 0.347 & 27 \\
\hline 2 & 4.8 & 0.490 & 50 & 11.131 & 10.948 & 0.000 & 0.169 & 1.000 & 0.831 & 0.333 & 0.376 & 0.355 & 26 \\
\hline 3 & 4.8 & 0.490 & 55 & 11.687 & 13.661 & 0.104 & 0.625 & 0.896 & 0.375 & 0.358 & 0.572 & 0.465 & 19 \\
\hline 4 & 4.8 & 0.539 & 45 & 11.255 & 10.948 & 0.023 & 0.169 & 0.977 & 0.831 & 0.339 & 0.376 & 0.357 & 25 \\
\hline 5 & 4.8 & 0.539 & 50 & 11.265 & 11.390 & 0.025 & 0.244 & 0.975 & 0.756 & 0.339 & 0.398 & 0.368 & 23 \\
\hline 6 & 4.8 & 0.539 & 55 & 11.985 & 11.841 & 0.159 & 0.320 & 0.841 & 0.680 & 0.373 & 0.424 & 0.398 & 22 \\
\hline 7 & 4.8 & 0.588 & 45 & 11.655 & 11.841 & 0.098 & 0.320 & 0.902 & 0.680 & 0.357 & 0.424 & 0.390 & 24 \\
\hline 8 & 4.8 & 0.588 & 50 & 11.678 & 12.251 & 0.102 & 0.388 & 0.898 & 0.612 & 0.358 & 0.450 & 0.404 & 20 \\
\hline 9 & 4.8 & 0.588 & 55 & 12.087 & 12.019 & 0.178 & 0.349 & 0.822 & 0.651 & 0.378 & 0.435 & 0.406 & 21 \\
\hline 10 & 5.9 & 0.490 & 45 & 14.539 & 13.172 & 0.635 & 0.543 & 0.365 & 0.457 & 0.578 & 0.523 & 0.550 & 13 \\
\hline 11 & 5.9 & 0.490 & 50 & 13.967 & 13.223 & 0.529 & 0.552 & 0.471 & 0.448 & 0.515 & 0.527 & 0.521 & 17 \\
\hline 12 & 5.9 & 0.490 & 55 & 13.876 & 13.733 & 0.512 & 0.637 & 0.488 & 0.363 & 0.506 & 0.580 & 0.543 & 15 \\
\hline 13 & 5.9 & 0.539 & 45 & 13.355 & 13.375 & 0.415 & 0.577 & 0.585 & 0.423 & 0.461 & 0.542 & 0.501 & 18 \\
\hline 14 & 5.9 & 0.539 & 50 & 14.213 & 13.724 & 0.574 & 0.636 & 0.426 & 0.364 & 0.540 & 0.579 & 0.559 & 12 \\
\hline 15 & 5.9 & 0.539 & 55 & 14.448 & 13.733 & 0.618 & 0.637 & 0.382 & 0.363 & 0.567 & 0.580 & 0.573 & 11 \\
\hline 16 & 5.9 & 0.588 & 45 & 14.040 & 13.274 & 0.542 & 0.560 & 0.458 & 0.440 & 0.522 & 0.532 & 0.527 & 16 \\
\hline 17 & 5.9 & 0.588 & 50 & 14.213 & 13.488 & 0.574 & 0.596 & 0.426 & 0.404 & 0.540 & 0.553 & 0.547 & 14 \\
\hline 18 & 5.9 & 0.588 & 55 & 14.499 & 14.000 & 0.628 & 0.682 & 0.372 & 0.318 & 0.573 & 0.612 & 0.592 & 10 \\
\hline 19 & 7.0 & 0.490 & 45 & 15.087 & 13.442 & 0.737 & 0.589 & 0.263 & 0.411 & 0.656 & 0.549 & 0.602 & 7 \\
\hline 20 & 7.0 & 0.490 & 50 & 15.239 & 13.708 & 0.766 & 0.633 & 0.234 & 0.367 & 0.681 & 0.577 & 0.629 & 9 \\
\hline 21 & 7.0 & 0.490 & 55 & 15.174 & 14.486 & 0.754 & 0.764 & 0.246 & 0.236 & 0.670 & 0.679 & 0.675 & 4 \\
\hline 22 & 7.0 & 0.539 & 45 & 15.012 & 14.629 & 0.723 & 0.788 & 0.277 & 0.212 & 0.644 & 0.702 & 0.673 & 5 \\
\hline 23 & 7.0 & 0.539 & 50 & 15.039 & 14.151 & 0.729 & 0.708 & 0.271 & 0.292 & 0.648 & 0.631 & 0.640 & 8 \\
\hline 24 & 7.0 & 0.539 & 55 & 16.496 & 14.757 & 1.000 & 0.810 & 0.000 & 0.190 & 1.000 & 0.724 & 0.862 & 2 \\
\hline 25 & 7.0 & 0.588 & 45 & 14.948 & 14.505 & 0.712 & 0.767 & 0.288 & 0.233 & 0.634 & 0.682 & 0.658 & 6 \\
\hline 26 & 7.0 & 0.588 & 50 & 15.629 & 15.891 & 0.838 & 1.000 & 0.162 & 0.000 & 0.756 & 1.000 & 0.878 & 1 \\
\hline 27 & 7.0 & 0.588 & 55 & 15.839 & 15.278 & 0.878 & 0.897 & 0.122 & 0.103 & 0.803 & 0.829 & 0.816 & 3 \\
\hline
\end{tabular}

Based on ranking order obtained from Table 9 and Fig.9, experiment no.26 is considered the best response value. Basically, larger the GRG, better will be corresponding characteristics.

\section{CONCLUSIONS}

The objective of the current research work is to optimize spot welding process parameters like welding current, electrode force and welding time for tensile shear strength and nugget diameter as response variables. The conclusions based on multi objective optimization using Taguchi with GRA are
Summarized as follows:

- The optimized input process parameters to get both maximum T-S and N-D values are A3B3C3 i.e. welding current $7 \mathrm{KA}$, Electrode force $0.588 \mathrm{KN}$ and welding time 55 cycle.

- ANOVA shows that welding current is most significant process parameter among three input process parameters for both the response variables.

- The improvement of grey relational grade for optimal process parameter is found to be 0.10 . 
M.R. Rawal et.al ," Optimization of Resistance Spot Welding of 304 Steel Using GRA", International Journal of Computer Engineering In Research Trends, Volume 3, Issue 9, September-2016, pp. 492-499

\section{ACKNOWLEDGE}

The authors hereby want to acknowledge Walchand College of engineering, Sangli, for permitting to conduct experimental trials on resistance spot welding. Author also wants to acknowledge Dr. J.J. MagdumCollege of engineering, Jaysingpur for giving permission to take readings on optical profile projector.

\section{REFERENCES:}

[1] A. V. Dennison, D. J. Toncich, and S. Masood, Control and Process-Based Optimization of Spot-Welding in Manufacturing Systems, International Journal of Advance Manufacturing Technology, 1997, 13, p 256-263.

[2] U. Esme, Application of Taguchi Method for the Optimization of Resistance Spot Welding Process, The Arabian Journal for Science and Engineering, 2008, 34, p 519-528.

[3] A. G. Thakur, and V. M. Nandedkar, Application of Taguchi Method to Determine Resistance Spot Welding Condition of Austenitic Stainless Steel AISI 304, Journal of Scientific and Industrial Research, 2010, 69, p 680-683.

[4] N. Muhammad, and H. P. Manurung, Design Parameters Selection and Optimization of Weld Zone Development in Resistance Spot Welding, World Academy of Science, Engineering and Technology, 2012, 72, p1220-1225.

[5] D. Das., A. Sahoo, R. Das, and B. Routara, Investigations on Hard Turning Using Coated Carbide Insert: Grey based Taguchi and Regression Methodology, Procedia Material Science, 2014, 6, p 1351-1358.

[6] M. Durairaj, D. Sudharsun, and N. Swamynathan, Analysis of Process Parameters in Wire EDM with Stainless Steel using Single Objective Taguchi Method and Multi Objective Grey Relational Grade, Procedia Engineering, 2013, 64 , p 868-877.

[7] J.L. Lin, and C. L. Lin, The Use of The Orthogonal Array With Grey Relational Analysis to Optimize the Electrical Discharge Machining Process With Multiple Performance Characteristics," International Journal of Machine Tools and Manufacture, 2002, 42, p 237- 244 .

[8] C. L. Lin, J. L. Lin, and T. C. Ko, Optimization of the EDM Process Based on the Orthogonal Array with Fuzzy Logic and Grey Relational Analysis Method, International Journal of Advanced Manufacturing Technology, 2002, 19, p 271-277.

[9] N. Tosun, Determination of Optimal Parameter for MultiPerformance Characteristics in Drilling by Using Grey Relational Analysis, International Journal of Advanced Manufacturing Technology, 2006, 28, p 450-455.

[10] U. A. Dabade, Multi-objective Process Optimization to Improve Surface Integrity on Turned Surface of $\mathrm{Al} / \mathrm{SiCp}$ Metal Matrix Composites Using Grey Relational Analysis, Procedia CIRP, 2013, 7, p 299-304.

[11] A.S Shivade, and V.D Shinde, Multi-objective Optimization in WEDM of D3 Tool Steel Using Integrated Approach of Taguchi Method and Grey Relational Analysis, Journal of Industrial Engineering international, 2014, 10, p 149-162.

[12] R. Kolhapure, V. D. Shinde and V. A. Kamble, Optimization of Strain Gauge Transducer for Weighing Application Using GRA Method, Asian Journal of Engineering and Applied Technology, 2015, 4, p 1-7. 